\title{
Modified Coated Copper Wire as a New Fiber for SPME-GC Analysis of Some Polycyclic Aromatic Hydrocarbons
}

\author{
Akram Masoumi, Maryam Abbasian, M. Moharamzadeh, Hossein Salar Amoli* \\ Nano Layer Coating Lab, Iranian Research Organization for Science and Technology (IROST), Tehran, Iran \\ Email: "salar@irost.org
}

Received 19 February 2016; accepted 13 June 2016; published 16 June 2016

Copyright @ 2016 by authors and Scientific Research Publishing Inc.

This work is licensed under the Creative Commons Attribution International License (CC BY).

http://creativecommons.org/licenses/by/4.0/

(c) (i) Open Access

\section{Abstract}

In this study for the first time, a novel copper Solid Phase Microextraction (SPME) fiber has been introduced for removal of naphthalene, phenanthrene and anthracene from aqueous solution. Copper was used as a solid support, which was at first coated by 3-mercaptopropyltrimethoxysilane. A stationary phase of oxidized multi walled carbon nanotube (MWCNTs)) was bonded to the surface of the copper wire. The developed SPME was characterized by IR and Scanning Electron Microscopy (SEM) and coupled to gas chromatography for separation of the analytes. Stability of the fiber, the effect of coating thickness and recovery time were optimized. The MWCNTs film thickness was about $5 \mu \mathrm{m}$ which was perfect for a rapid mass transfer. The detection limits were at the range of 0.005 to $0.1 \mu \mathrm{g} \cdot \mathrm{L}^{-1}$. The calibration curves were linear $R^{2}>0.9813$ in the range of 0.01 to $5 \mu \mathrm{g} \cdot \mathrm{L}^{-1}$. The method has been successfully applied for real samples with standard addition of $5 \mathrm{~L}^{-1}$ of each sample. Stability study of the fiber to acid and alkali shows that it can be used for more than 50 times.

\section{Keywords}

Gas Chromatography, Solid Phase Micro Extraction, Coated Copper Wire, Polycyclic Aromatic Hydrocarbons, Carbon Nanotube

\section{Introduction}

Application of new fiber has been investigated in recent years to enhance durability and sensitivity of the solid phase microextraction fiber [1]-[5]. Since most of these new fibers are expensive and fragile, many researchers

\footnotetext{
${ }^{*}$ Corresponding author.
}

How to cite this paper: Masoumi, A., Abbasian, M., Moharamzadeh, M. and Amoli, H.S. (2016) Modified Coated Copper Wire as a New Fiber for SPME-GC Analysis of Some Polycyclic Aromatic Hydrocarbons. Materials Sciences and Applications, 7, 316-325. http://dx.doi.org/10.4236/msa.2016.76029 
are focusing to provide stable, rigid and low cost fibers [6]-[9].

In recent years the contamination of drinking water and agricultural resources by Polycyclic Aromatic Hydrocarbons (PAHs) is one of the major environmental problems in the world. PAH composed of two or more benzene rings. The main source of these compounds is incomplete combustion of carbon-containing compounds such as oil, wood, waste or fuel [10]. These compounds are toxic and carcinogenic, especially when connected to a biological chain. They can be solid or liquid effluents, or diffusing through the atmosphere into the environment. These compounds are hydrophobic and electrochemically very stable, have high melting and boiling temperatures. Also they are stable in soil and water and can be accumulated for a long time [11]. Excessive exposure to these compounds can cause disturbances in the central nervous system, irritation of the eyes, upper respiratory tract irritation, hardening of the skin, blood disorders and anemia [12]. According to the standards adopted by the European Union, the concentration of PAH compounds in drinking water should be less than 100 $\mathrm{ng} \cdot \mathrm{L}^{-1}$. Therefore, identification and continuous measurement of low concentrations of these compounds in water is crucial for health [13]. Considering the above, efficient and accurate, simple and inexpensive method to detect trace amounts of these compounds, is necessary and much research has been done for the removal of these pollutants from water [14]-[16].

Solid Phase Microextraction (SPME), has been developed by Arthur and Pawliszyn at the University of Waterloo in 1990 [17] and successfully used for the extraction of gas, liquid and solid, volatile and nonvolatile organic compounds from samples of soil, water and air [18]. This method is fast because the condensation and separation of analytes could be achieved in one step and the fibers can be used for several times, which makes them affordable and cheap. This method is solvent free, portable and relatively independent of the design of a complex system and can be assembled fully automatic. The method can detect concentrations of pollutant with ppb levels and be easily connected to GC and HPLC. So that it can be used to separate volatile and semi-volatile organic compounds in nature [19]. SPME separation process is based on the partition of analytes between the fiber and the sample solution. Fiber consists of a small needle which is coated with a thin layer of polymer, and a final coating material. Solute absorption by SPME could be achieved either by direct extraction or head space method [10]. Fiber type and coating thickness and selectivity determine the efficiency and separation of the analytes. Also, the selectivity determines the partition coefficient between the fiber and analyte matrix [20]-[22]. In general, it can be said that adsorption efficiency mainly depends on physical and chemical properties of sorbent and pollutant compounds.

Carbon nano materials are an effective absorbent that is widely used to trap the aromatic compounds. Carbon nanotubes (CNTs) are a new type of carbon nano materials that was first discovered in 1991 by Iijima [23]. Because of the unique geometry, high mechanical strength, thermal stability and a high surface area, compared to other absorbents, CNTs is highly considered by the researchers [22] [23]. Hydrophobic surface of CNT provides stronger absorbing properties than carbon nano materials for different combinations. Aromatic compounds are absorbed by CNTs with physical interaction without charge transfer between the adsorbent and adsorb. The presence of electron donor groups such as $\mathrm{NH}_{2}, \mathrm{COOH}$ and $\mathrm{OH}$ in CNTs surface increases the absorption efficiency and causes strong $\pi-\pi$ interactions between the CNTs and the benzene ring [23]. Because of the diameter of the nano and molecular structure of CNTs, these compounds can placed as a bridge between molecules and diagnostic equipment and related information of biological processes could be delivered as a measurable signs [24].

The chemical bonding of CNTs onto a solid support is quite efficient to fabricate a fiber with some special properties, such as thermal and chemical stability in high temperature and organic solvent, acid and alkali solution, without loss of performance [25]-[28].

In this study a new method was developed to prepare chemically bonded CNTs coating on modified copper surface to absorb low concentration of polycyclic aromatic hydrocarbons. Comparing to other metallic wires (e.g. gold, silver, ...) the copper wire is less expensive. Also it possesses a higher hardness and good electron mobility. The fiber is successfully applied to the solutes and various parameters have been studied. The fiber is then connected to the gas chromatograph for further analysis.

\section{Experimental}

\subsection{Materials and Instruments}

The copper wire was obtained from the Yixing Shenglang Metal Wire Net Co. (China). 
3-mercaptopropyletrimetoxysilane (3-MPTS), standard material of PAH, solvents, sodium chloride and HPLC grade methanol were purchased from Merck. MWCNTs were obtained from Research Institute of Petroleum Industry of Iran. All chemicals were of analytical grade.

A capillary gas chromatograph with flame ionization detector and split-splitless device was used to determine extracted solutes (Model SHIMADZU 2010). The quantitative measurement carried out using standard analyte solutions and measurement of the peak area.

Surface characterization of the copper-coated fiber is obtained by a SEM (JSM-5600 LV, Jeol Ltd.).

\subsection{Preparation of Coating Layer}

$1 \mathrm{~g}$ MWCNTs was first purified with $\mathrm{HCl}(8 \%)$ for $24 \mathrm{~h}$ so as to remove the metal ions and other impurities, then refluxed in $20 \mathrm{ml} \mathrm{HNO}_{3} 65 \%$ at $85^{\circ} \mathrm{C}$ for $8 \mathrm{~h}$ with vigorous stirring. The mixture was washed with purified water to $\mathrm{pH} 7$ and filtered. MWCNTs were dried under vacuum at $40^{\circ} \mathrm{C}$ for $4 \mathrm{~h}$.

\subsection{Surface Modification of Copper Wires}

The copper wires with length of $10 \mathrm{~cm}$ and thickness of $200 \mu \mathrm{m}$ were prepared and washed with acetone and 1 $\mathrm{mol} \cdot \mathrm{L}^{-1} \mathrm{NaOH}$ for $10 \mathrm{~min}$. Then one end of wire immersed into $20 \mathrm{mmol} \cdot \mathrm{L}^{-1}$ of 3-MPTS in toluene for $24 \mathrm{~h}$ to form self-assembled molecule film. The thiol groups of the 3-MPTS have great tendency to react with copper. Then, it was taken out and dried at room temperature for $2 \mathrm{~h}$.

$1 \mathrm{mg}$ of MWCNTs dispersed in ethanol under sonication to prepare the MWCNTs suspension. Then the pretreated copper wire was refluxed with MWCNTs suspension for $24 \mathrm{~h}$ in a hot water bath $\left(70^{\circ} \mathrm{C}\right)$, and then it was placed in a $120^{\circ} \mathrm{C}$ oven under the flow of dry nitrogen for $1 \mathrm{~h}$.

\subsection{Sample Preparation}

Stock solutions were prepared by dissolving analytes in methanol separately, to obtain $100 \mathrm{mg} \mathrm{L}^{-1}$ of each analyte. They were stored at $4^{\circ} \mathrm{C}$. For extraction optimization, the stock solution was diluted with specified solvents to desired concentration.

The ground water samples were collected from Shahriar city, west of Tehran. These samples were all filtered through a $0.45 \mu \mathrm{m}$ filter and collected into sealed vials and stored at $4^{\circ} \mathrm{C}$.

\subsection{Solid Phase Microextraction}

The extractions were performed in direct-immersion mode with $10 \mathrm{ml}$ aqueous solution in a $15 \mathrm{ml}$ vial. Working solutions were prepared daily by diluting the stock solutions. A magnetic stirring bar was put in the vial to accelerate the mass transfer to fiber. After the extraction, the fiber washed with $5 \mathrm{ml}$ methanol and injected to GC. Extraction conditions such as time, temperature, ionic strength, agitation rate and desorption conditions were investigated and optimized.

\section{Results and Discussion}

\subsection{Copper Coated SPME Fiber}

Copper wire is hard, chemically inert and thermally resistance, which can improve the stability and life time of SPME fiber. Using copper wires with respect to relativistic effect and relevance in chemistry increases the mobilization of electrons and facilitates the formation of chemical bond and easily modified by organic molecules. In this research, we have taken these advantages to chemically binding CNTs on the copper surface. The substrate, copper wire, was activated to ensure removing the organic filth and oxide layer for uniformity and firmness of the coating films and then immersed in the polymer (3-MPTS). This method creates, stable and non-brittle coating which can be used several times and in terms of affordable.

The carbon nanotube was oxidized by acids to create - $\mathrm{COOH}$ and $\mathrm{OH}$ groups at the wall of the CNTs and chemically coated on the surface of the copper wire. The chemical process is shown in Figure 1.

\subsection{Characterization of Modified Copper Wire}

After preparation of the novel modified copper wire, the feasibility tests were applied. 


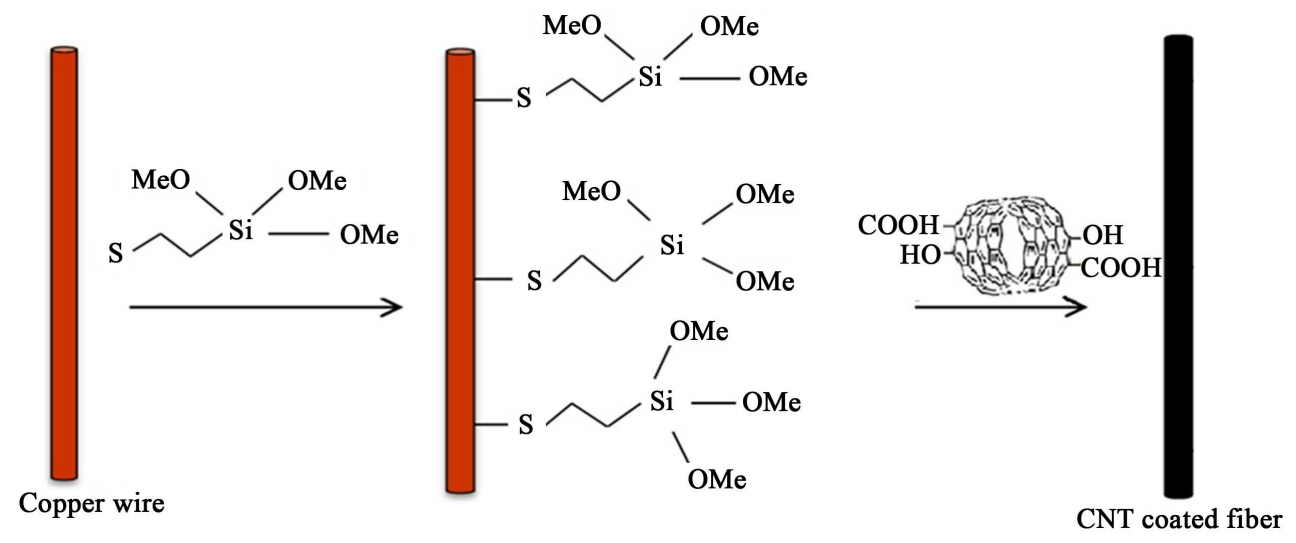

Figure 1. Schematic illustration of the preparation process of the copper-MWCNTs fiber.

At first the fiber was characterized by IR spectroscopy. As it is shown in Figure 2(A), the peaks of $\mathrm{C}=\mathrm{O}$ and $\mathrm{C}=\mathrm{C}$ is recognized at 1629 and $1564 \mathrm{~cm}^{-1}$ corresponding to oxidized MWCNTs (MWCNTS-COOH), while in Figure 2(B), for the pure- MWCNTs there are absent. Also the surface characteristic of modified fiber was investigated using scanning electron microscopy (SEM). Figure 3 shows that the coating has a porous structure which provides a high surface area and causes a higher extraction efficiency. The thickness is about 5 to $12 \mu \mathrm{m}$ which is thin enough to allow a fast mass transfer.

\subsection{Optimization of Parameters.}

For efficiency evaluation of the constructed fiber, several parameters have been investigated. Since extraction temperature and agitation effect have a great influence on the absorption of extracted analytes, at first these parameters have been studied.

\subsubsection{The Effect of Temperature}

Figure 4 shows that there are optimum temperatures where the highest analyte absorption peak can be obtained. Increasing the temperature causes more mobility and mass transfer, but a very high temperature causes the solvent (methanol), evaporate and remove some analytes and reduce the extraction efficiency. In fact temperature has a twofold impact on the extraction and both of them are important. Highest temperature increase molecular movement, thereby causes an increasing in mass transfer and decreasing the equilibrium time. But partition coefficients of analytes between the fiber and the sample matrix decrease. In very low temperature, the mass transfer decreases and causes lower efficiency. In this study extraction temperature tested from $30^{\circ} \mathrm{C}$ to $70^{\circ} \mathrm{C}$. Figure 4 shows that the best temperature for highest extraction efficiency is at $50^{\circ} \mathrm{C}$.

\subsubsection{Agitation Studies}

Agitation effect on the extraction efficiency is critical as well. It causes faster mass transport of the analytes from the sample matrix to fiber surface. Agitation reduces the thickness of the boundary layer around the fiber coating that implies shorter equilibrium time and higher extraction efficiency. It was shown that stirring with the magnetic agitator of 400 - $800 \mathrm{rpm}$ increased the mass transfer of the analyte to fiber (Figure 5). So a fix stirring rate of $700 \mathrm{rpm}$ was chosen for this analysis.

\subsubsection{Thin Layer Thickness Effect}

To find the best thickness, various concentrations of coating Layer of CNTs were investigated. The extraction performance is increased by increasing the CNTs concentration. Although the thick coating has high extraction capacity, the thinner coated surface could provide the best mass transfer. So, in this research work a thickness of $5 \mu \mathrm{m}$ has been used for further experiments.

\subsubsection{Evaluation of Fiber Stability.}

The stability of the copper-MWCNTs fiber was investigated using harsh treatments. For this purpose the fiber 


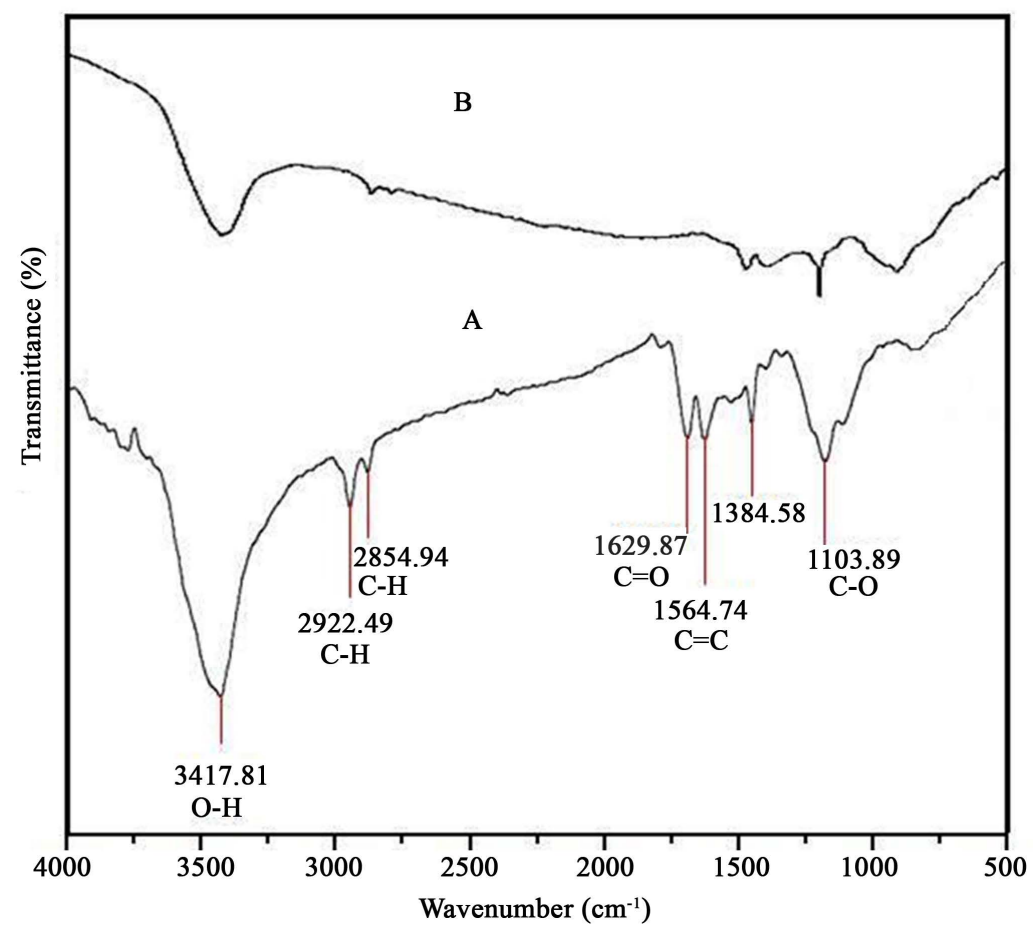

Figure 2. IR spectra of (A) MWCNTs -COOH (B) Pure MWCNTs.

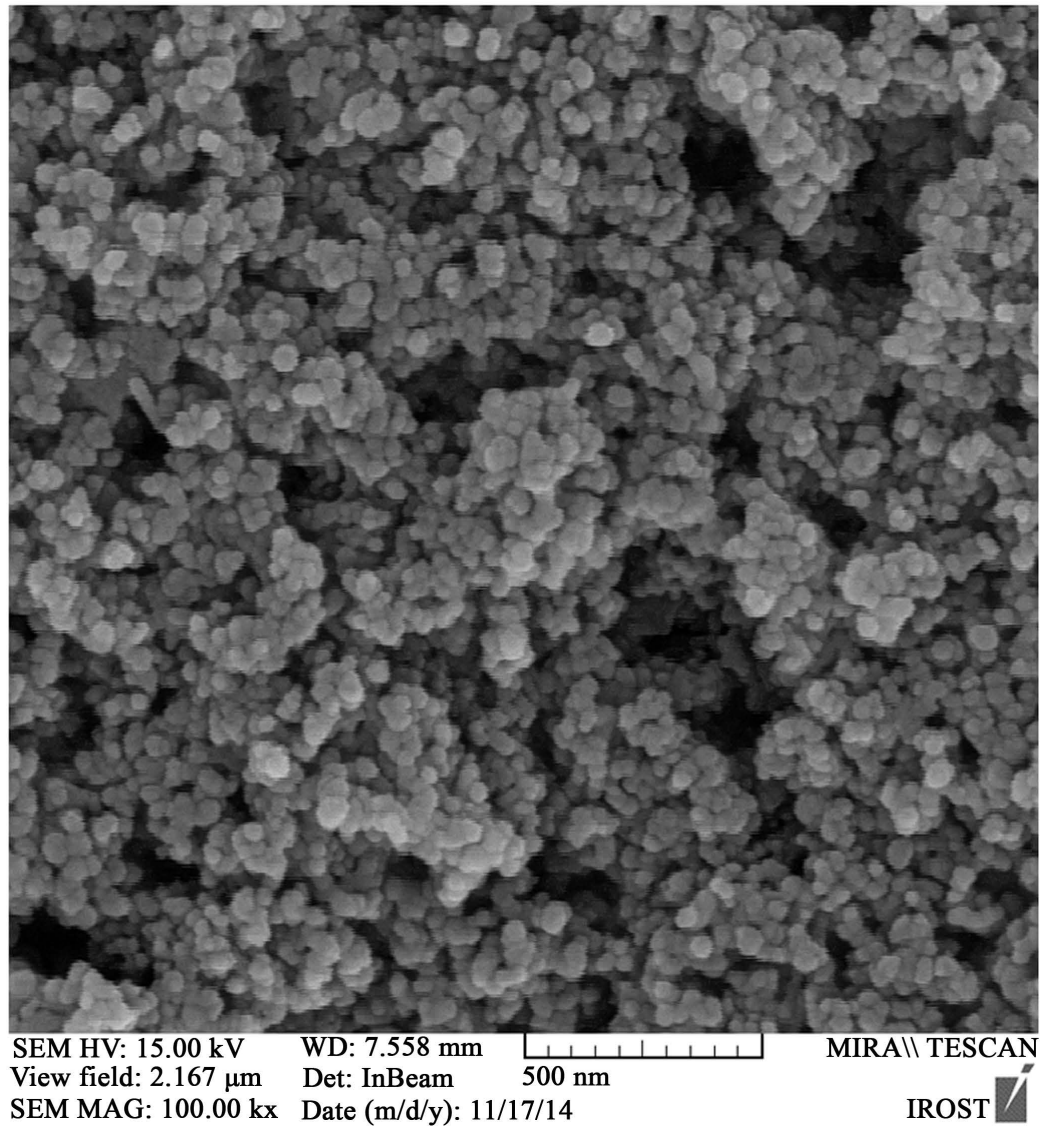

Figure 3. SEM image of the copper-coated SPME fiber. 


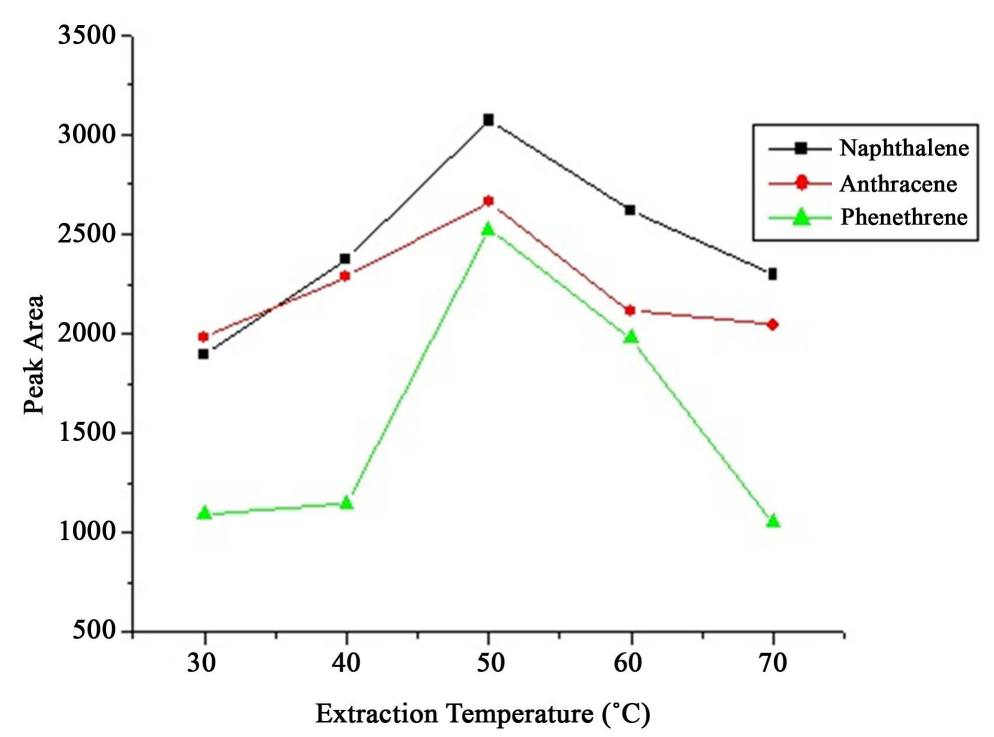

Figure 4. The effect of extraction temperature on extraction efficiency. Conditions; extraction time $40 \mathrm{~min}$, content of KCl; $20 \%$ (w/v), stirring rate; 700 rpm.

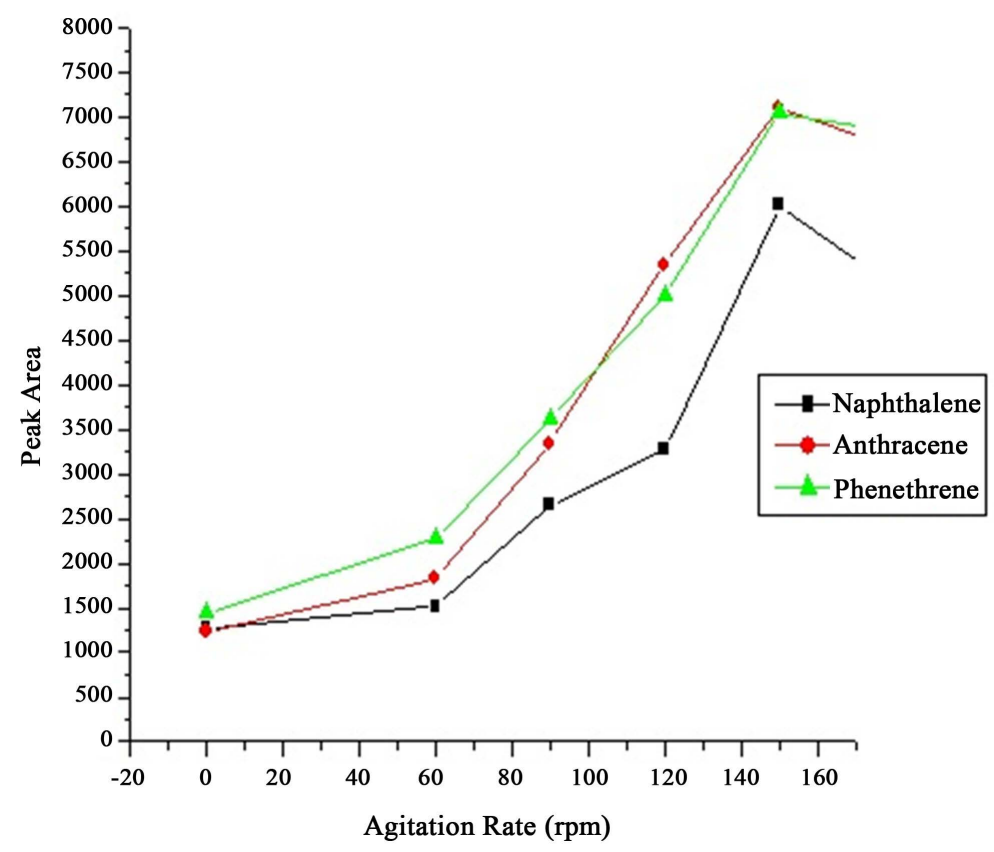

Figure 5. Agitation effect on the extraction efficiency; Conditions; extraction time; 40 min, extraction temperature; $50^{\circ} \mathrm{C}$, content of $\mathrm{KCl} ; 20 \%(\mathrm{w} / \mathrm{v})$.

immersed into $0.01 \mathrm{M} \mathrm{NaOH}$ and $0.01 \mathrm{M} \mathrm{HCl}$ for 24 hours and the extraction efficiency were calculated. It was found that, up to 50 times usage of the fiber, there are not any significant changes in the absorption of naphthalene, phenanthrene and anthracene. So it can be concluded that the fiber is well stable and durability to acid and alkali is acceptable.

The efficiency of the SPME fiber is based on reaching equilibrium and depends on time of extraction. So the optimum extraction time has directly effect on the extraction efficiency. This factor was investigated from 0 to 70 minutes and as shown in Figure 6, highest extraction efficiency was obtained in 40 min.

Addition of soluble salts to the solution, increases the ionic strength and the distribution constant. Different ionic strength was obtained with different $\mathrm{KCl}$ concentrations from 0 to $30 \mathrm{wt} \%$. As shown in Figure 7, peak 


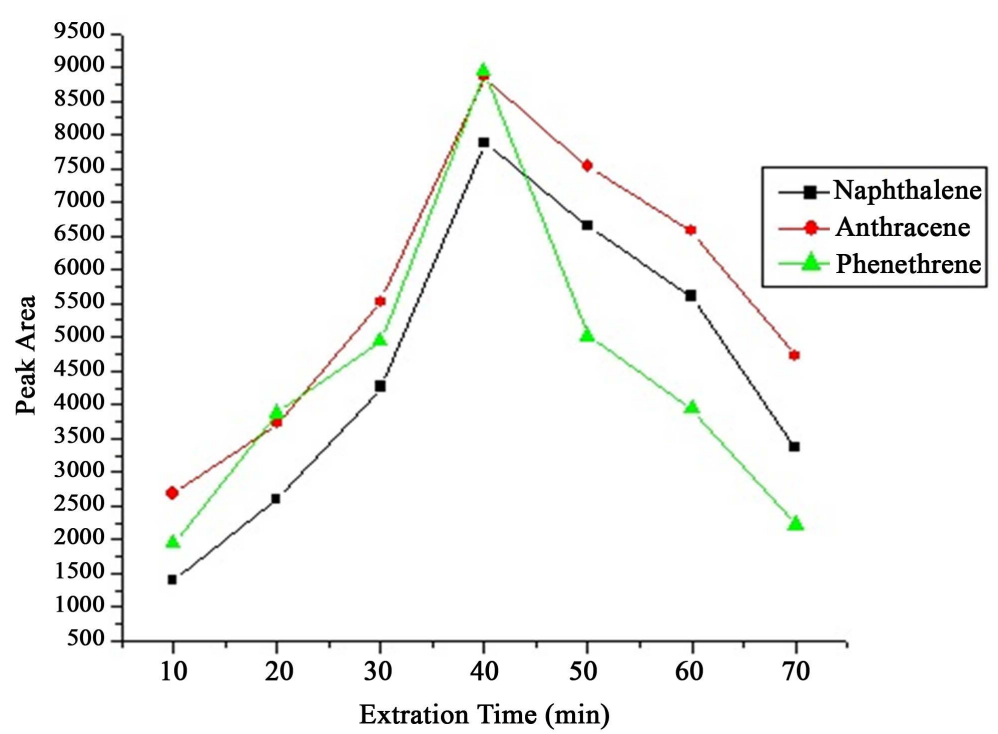

Figure 6. Dependency of extraction efficiency on extraction time. Conditions; extraction temperature; $50^{\circ} \mathrm{C}$, content of $\mathrm{KCl} ; 20 \%$ (w/v). stirring rate; $700 \mathrm{rpm}$.

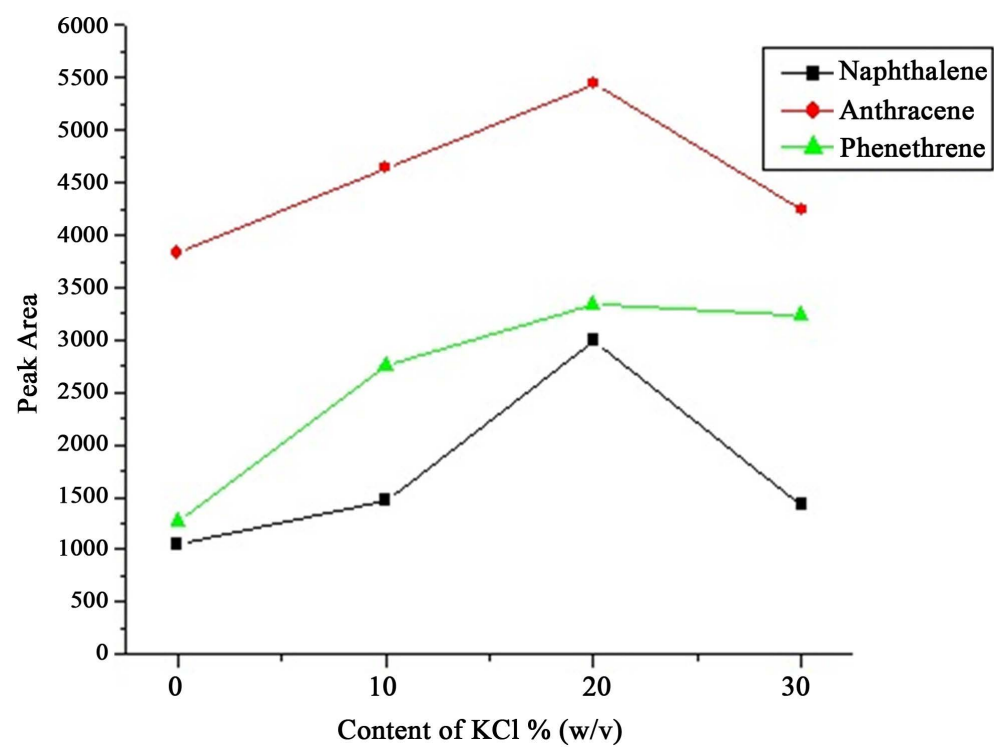

Figure 7. Effect of ionic strength on peak area. Conditions; extraction time; $40 \mathrm{~min}$; extraction temperature; $50^{\circ} \mathrm{C}$; stirring rate; $700 \mathrm{rpm}$.

area increases with higher concentration of $\mathrm{KCl}$ from 0 to $20 \mathrm{wt} \%$. Thereby $20 \mathrm{wt} \%$ salt was chosen as the best content of $\mathrm{KCl}$ in working solution.

\subsection{Analytical Evaluation}

The developed method was evaluated for the separation and determination of naphthalene, phenanthrene and anthracene from aqueous solutions at room temperature. To establish the optimum conditions, stirring rate of $700 \mathrm{rpm}$, deposition time of $40 \mathrm{~min}$ and salt concentration of $20 \%$ selected. In these conditions the calibration curves were linear in the range of 0.01 to $5 \mu \mathrm{g} \cdot \mathrm{L}^{-1}$ and regression coefficient for analytes were $\mathrm{R}^{2}>0.9813$, 0.9656, and 0.9723 for naphthalene, phenanthrene and anthracene respectively. The limits of detection were between 0.005 and $0.1 \mu \mathrm{g} \cdot \mathrm{L}^{-1}$ based on signal to noise ratio of 3/1. The SPME-GC spectrum of the separated analytes is shown in Figure 8. The peaks are separated and allow for a quantitative analysis. 


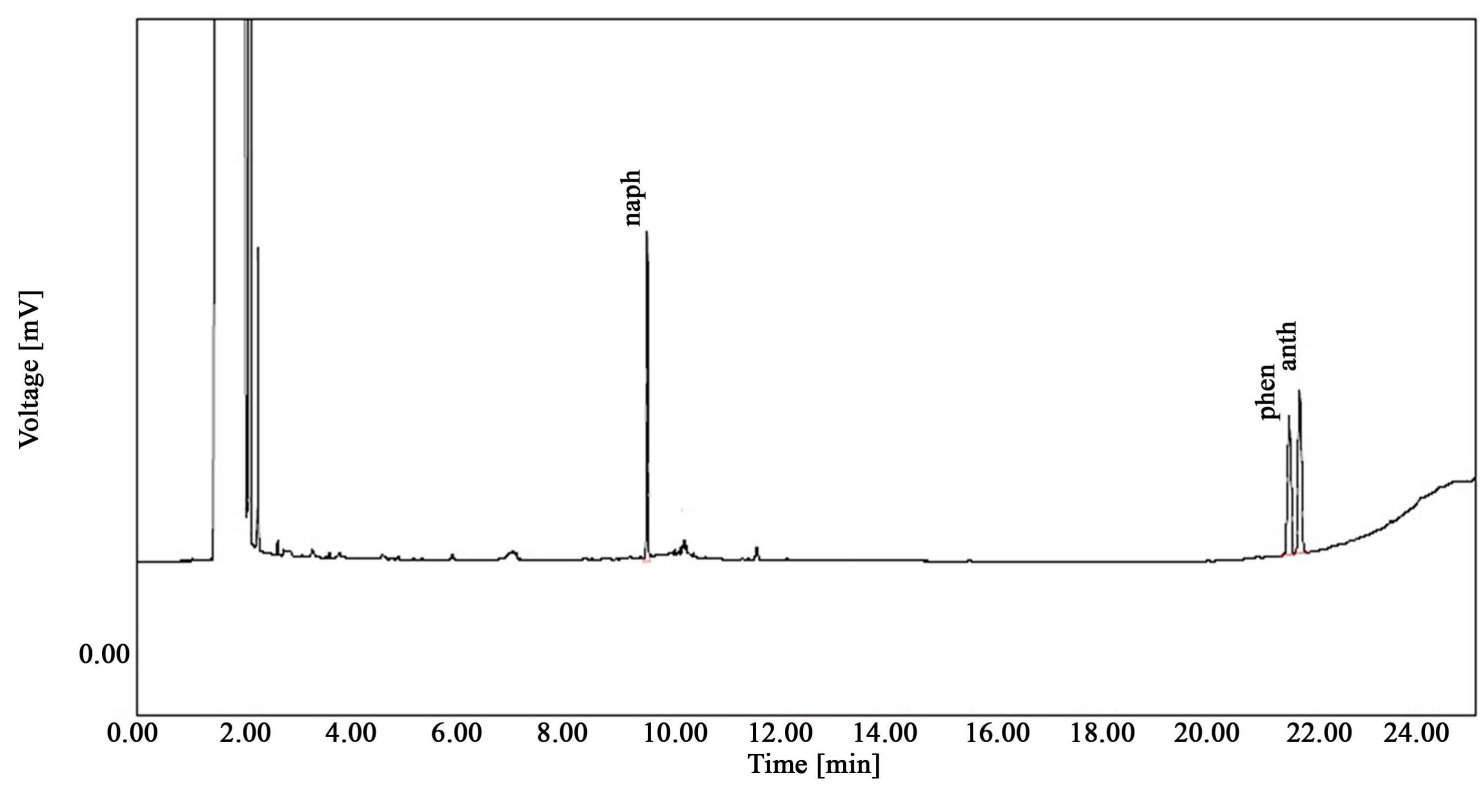

Figure 8. GC chromatogram of analytes using Copper-MWCNTs as SPME fiber.

The developed method was applied for extraction and analysis of samples from ground water in Shahriar (west of Tehran). The samples were spiked with $5 \mu \cdot \mathrm{L}^{-1}$, and the relative recoveries of 87 to $110 \%$, 92 to $104 \%$ and 89 to $108 \%$ were obtained for naphthalene, phenanthrene and anthracene respectively. The results show that analytical characteristics of the proposed new fiber are comparable with reported articles [29]-[32].

\section{Conclusion}

A novel SPME fiber was constructed using copper wire as substrate which was coated by functionalized MWCNTs. The fiber has porous structure and large surface area for increasing extraction efficiency. The novel copper-MWCNTs fiber has a long operation life and can be used for more than 50 times. The results indicate that the fiber has a good thermal and chemical stability, high extraction efficiency and high capability for adsorption and separation of polycyclic aromatic hydrocarbons in aqueous, real solutions.

\section{References}

[1] Farajzadeh, M.A. and Matin, A.A. (2008) Determination of BTEX in Water Samples with an SPME Hollow Fiber Coated Copper Wire. Chromatographia, 68, 443-446. http://dx.doi.org/10.1365/s10337-008-0726-z

[2] Safarzadeh-Yazdi, H., Sepehr, S., Eshaghi, Z. and Piri Moghadam, H. (2010) Chromatographia, 72, 4524-4537.

[3] Gbatu, T.P., Sutton, K.L. and Caruso, J.A. (1999) Development of New SPME Fibers by Sol-Gel Technology for SPME-HPLC Determination of Organometals. Analytica Chimica Actaa, 402, 67-79. http://dx.doi.org/10.1016/S0003-2670(99)00532-2

[4] Djozan, D. and Ebrahimi, B. (2008) Preparation of New Solid Phase Micro Extraction Fiber on the Basis of Atrazine-Molecular Imprinted Polymer: Application for GC and GC/MS Screening of Triazine Herbicides in Water, Rice and Onion. Analytica Chimica Acta, 616, 152-159. http://dx.doi.org/10.1016/j.aca.2008.04.037

[5] Gholivand, M.B., Abolghasemi, M.M. and Fattahpour, P. (2011) A Hexagonally Ordered Nanoporous Silica-Based Fiber Coating for SPME of Polycyclic Aromatic Hydrocarbons from Water Followed by GC-MS. Chromatographia, 74, 807-815. http://dx.doi.org/10.1007/s10337-011-2146-8

[6] Bagheri, H., Mir, A. and Babanezhad, E. (2005) An Electropolymerized Aniline-Based Fiber Coating for Solid Phase Microextraction of Phenols from Water. Analytica Chimica Acta, 532, 89-95. http://dx.doi.org/10.1016/j.aca.2004.10.040

[7] Wang, W.-D., Huang, Y.-M., Shu, W.-Q. and Cao, J. (2007) Multiwalled Carbon Nanotubes as Adsorbents of SolidPhase Extraction for Determination of Polycyclic Aromatic Hydrocarbons in Environmental Waters Coupled with High-Performance Liquid Chromatography. Journal of Chromatography A, 1173, 27-36. http://dx.doi.org/10.1016/j.chroma.2007.10.027 
[8] Maleki, R., Farhadi, K. and Tahmasebi, R. (2009) Preparation of a Sol-Gel Titania Based Coating for HS-SPME of Aliphatic Alcohols from Non-Alcoholic Beer Samples. Chromatographia, 69, 775-778. http://dx.doi.org/10.1365/s10337-009-0964-8

[9] Zhang, Z., Duan, H., Zhang, L., Chen, X., Liu, W. and Chen, G. (2009) Direct Determination of Anabolic Steroids in Pig Urine by a New SPME-GC-MS Method. Talanta, 78, 1083-1089. http://dx.doi.org/10.1016/j.talanta.2009.01.022

[10] Cioroiu, B.I., Cioroiu, M.E., Tarcau, D. and Tomoiaga, A.M. (2014) Determination of PAHS in Lung Tissue Samples Using Specific Chromatographic Techniques: Method Development and Validation. Journal of Liquid Chromatography \& Related Technologies, 35, 713-725. http://dx.doi.org/10.1080/10826076.2012.758139

[11] Zhu, T., Ding, L., Gau, X., Yang, L. and Wen, A. (2007) Simultaneous Determination of Tramadol and Acetaminophen in Human Plasma by LC-ESI-MS. Chromatographia, 66, 171-178. http://dx.doi.org/10.1365/s10337-007-0268-9

[12] Moret, S., Dudine, A. and Conte, L.S. (2000) Processing Effects on the Polyaromatic Hydrocarbon Content of Grapeseed Oil. Journal of the American Oil Chemists' Society, 7, 1289-1292. http://dx.doi.org/10.1007/s11746-000-0203-5

[13] Zelinkora, Z. and Wenzl, T. (2015) The Occurrence of 16 EPA PAHs in Food-A Review. Polycyclic Aromatic Compounds, 35, 248-284. http://dx.doi.org/10.1080/10406638.2014.918550

[14] Bagheri, H., Ayazi, Z. and Babanezhad, E. (2010) A Sol-Gel-Based Amino Functionalized Fiber for Immersed SolidPhase Microextraction of Organophosphorus Pesticides from Environmental Samples. Microchemical Journal, 94, 1-6. http://dx.doi.org/10.1016/j.microc.2009.08.003

[15] Farhadi, K., Tahmasebi, R. and Maleki, R. (2009) Preparation and Application of the Titania Sol-Gel Coated Anodized Aluminum Fibers for Headspace Solid Phase Microextraction of Aromatic Hydrocarbons from Water Samples. Talanta, 77, 1285-1289. http://dx.doi.org/10.1016/j.talanta.2008.09.009

[16] Przybilla, L., Brand, J.-D., Yoshimura, K., Rader, H.S. and Mullen, K. (2000) MALDI-TOF Mass Spectrometry of Insoluble Giant Polycyclic Aromatic Hydrocarbons by a New Method of Sample Preparation. Analytical Chemistry, 72, 4591-4597. http://dx.doi.org/10.1021/ac000372q

[17] Arthur, C. and Pawliszyn, J. (1990) Solid Phase Microextraction with Thermal Desorption Using Fused Silica Optical Fibers. Analytical Chemistry, 62, 2145-2148. http://dx.doi.org/10.1021/ac00218a019

[18] Belardi, R.P. and Pawliszyn, J.B. (1989) Application of Chemically Modified Fused Silica Fibers in the Extraction of Organics from Water Matrix Samples and Their Rapid Transfer to Capillary Columns. Water Pollution Research Journal of Canada, 24, 179-191.

[19] Zhang, Z., Wang, X., Lin, C., Fang, G. and Wang, S. (2012) A Novel SPME Fiber Chemically Linked with 1-Vinyl3-hexadecylimidazolium Hexafluorophosphate Ionic Liquid Coupled with GC for the Simultaneous Determination of Pyrethroids in Vegetables. Chromatographia, 75, 789-797. http://dx.doi.org/10.1007/s10337-012-2244-2

[20] Liu, Y., Shen, Y.F. and Lee, M.L. (1997) Porous Layer Solid Phase Microextraction Using Silica Bonded Phases. Analytical Chemistry, 69, 190-195. http://dx.doi.org/10.1021/ac960791g

[21] Maghsoudi, S. and Noroozian, E. (2012) HP-SPME of Volatile Polycyclic Aromatic Hydrocarbons from Water Using Multiwalled Carbon Nanotubes Coated on a Steel Fiber through Electrophoretic Deposition. Chromatographia, 75, 913-921. http://dx.doi.org/10.1007/s10337-012-2283-8

[22] Li, Q., Ma, X., Yuan, D. and Chen, J. (2010) Evaluation of the Solid-Phase Microextraction Fiber Coated with Single Walled Carbon Nanotubes for the Determination of Benzene, Toluene, Ethylbenzene, Xylenes in Aqueous Samples. Journal of Chromatography A, 1217, 2191-2196. http://dx.doi.org/10.1016/j.chroma.2010.02.009

[23] Iijima, S. (1991) Helical Microtubules of Graphitic Carbon. Nature, 354, 56-58. http://dx.doi.org/10.1038/354056a0

[24] Kueseng, P., Thammakhet, C., Thavarungkul, P. and Kanatharana, P. (2010) Multiwalled Carbon Nanotubes/Cryogel Composite, a New Sorbent for Determination of Trace Polycyclic Aromatic Hydrocarbons. Microchemical Journal, 96, 317-323. http://dx.doi.org/10.1016/j.microc.2010.05.0,02

[25] Chen, Z.C., Zhang, L.S., Tang, Y.W. and Jia, Z.J. (2006) Adsorption of Nicotine and Tar from the Mainstream Smoke of Cigarettes by Oxidized Carbon Nanotubes. Applied Surface Science, 252, 2933-2937. http://dx.doi.org/10.1016/j.apsusc.2005.04.044

[26] Pillary, K., Cukrowska, E.M. and Coville, N.J. (2009) Multi-Walled Carbon Nanotubes as Adsorbents for the Removal of Parts per Billion Levels of Hexavalent Chromium from Aqueous Solution. Journal of Hazardous Materials, 166, 1067-1075. http://dx.doi.org/10.1016/j.jhazmat.2008.12.011

[27] Bagheri, H., Ayazi, Z. and Aghakbani, A. (2011) A Novel Needle Trap Sorbent Based on Carbon Nanotube-Sol-Gel for Microextraction of Polycyclic Aromatic Hydrocarbons from Aquatic Media. Analytica Chimica Acta, 683, 212-220. http://dx.doi.org/10.1016/j.aca.2010.10.026

[28] Sun, M., Feng, J., Oiu, H., Fan, L., Li, X. and Luo, C. (2013) CNT-TiO ${ }_{2}$ Coating Bonded onto Stainless Steel Wire as a Novel Solid-Phase Microextraction Fiber. Talanta, 114, 60-65. http://dx.doi.org/10.1016/j.talanta.2013.04.005 
[29] Aguinaga, N., Campillo, N., Vinas, P. and Hernandez, C. (2008) A Headspace Solid-Phase Microextraction Procedure Coupled with Gas Chromatography-Mass Spectrometry for the Analysis of Volatile Polycyclic Aromatic Hydrocarbons in Milk Samples. Analytical and Bioanalytical Chemistry, 391, 753-758. http://dx.doi.org/10.1007/s00216-008-1841-2

[30] Aziz-Zanjani, M.O. and Mehdinia, A. (2014) A Review on Procedures for the Preparation of Coatings for Solid Phase Microextraction. Microchimica Acta, 181, 1169-1190. http://dx.doi.org/10.1007/s00604-014-1265-y

[31] Spieteium, A., Pilarczyk, M., kloskowski, A. and Namiesnik, J. (2010) Current Trends in Solid-Phase Microextraction (SPME) Fibre Coatings. Chemical Society Reviews, 39, 4524-4537. http://dx.doi.org/10.1039/c003335a

[32] Djozan, D. and Assadi, Y. (2004) Modified Pencil Lead as a New Fiber for Solid-Phase Microextraction. Chromatographia, 60, 313-317. 